\title{
La selección de textos literarios en el contexto del español como segunda lengua. Investigación cualitativa con adolescentes inmigrantes
}

\author{
Virginia CALVO VALIOS \\ Universidad de Zaragoza \\ Departamento de Didáctica de las Lenguas y de las Ciencias Humanas y Sociales \\ vcalvo@unizar.es \\ Rosa TABERNERO SALA \\ Universidad de Zaragoza \\ Departamento de Didáctica de las Lenguas y de las Ciencias Humanas y Sociales \\ rostab@unizar.es
}

Recibido: 27 de noviembre de 2014

Aceptado: 6 de abril de 2015

\section{RESUMEN}

En este artículo se proponen claves de selección de textos literarios para adolescentes inmigrantes de niveles A2 de competencia comunicativa en español. El diseño de la investigación se configura a partir del paradigma cualitativo/interpretativo de corte etnográfico y de la investigación-acción en el escenario de cuatro aulas de español. El análisis de una muestra de treinta jóvenes inmigrantes ante el corpus leído durante el trabajo de campo, aporta seis variables menos centradas en la proyección explícita de la migración, y más sujetas al concepto de distancia como elemento transcendente de la lectura literaria.

Palabras clave: adolescentes inmigrantes, español como L2, lectura literaria, respuestas lectoras.

Selection of literary text in the context of Spanish as a Second Language. Qualitative research with immigrant teenagers

\begin{abstract}
This paper proposes key selection of literary texts for immigrant teenagers with A2 levels of communicative competence in Spanish. The design of investigation was shaped from a qualitative/ interpretive paradigm and court action research in four classrooms of Spanish as Second Language. The analysis of a sample of thirty young immigrants to the corpus read during the fieldwork, this brigs six variables less focused on explicit projection of migration, and more in regarding to the concept of distance as a transcendent element of the literary reading.
\end{abstract}


Key words: immigrant teenagers, Spanish as Second Language, literary reading, reading responses.

Le choix des textes littéraires dans le contexte de l'espagnol comme langue seconde. La recherche qualitative avec des adolescents immigrés

\section{RÉSUMÉ}

Cet article touches de sélection de textes littéraires pour adolescents immigrants niveaux A2 de la compétence communicative en espagnol sont proposés. Le plan de recherche est configuré à partir du paradigme recherche qualitative / interprétative ethnographique et l'action sur scène quatre classes espagnoles. L'analyse d'un échantillon d'une trentaine de jeunes immigrants au corpus lire lors de travaux sur le terrain, six variables contribue moins axée sur projection explicite de la migration, et sous réserve de la notion de distance comme élément transcendant de la lecture littéraire.

Mots-clés : adolescents immigrants, espagnol L2, lecture littéraire, les réponses de lecture.

SUMARIO: 1. Introducción; 2. Marco teórico; 3. Diseño de la investigación; 3.1. Contexto y participantes; 3.2. Metodología de la investigación; 3.3. Desarrollo de las sesiones; 3.4. Corpus literario experimentado; 4. Resultados; 5. Conclusiones; 6. Bibliografía.

\section{INTRODUCCIÓN}

En este artículo se presentan los resultados de una investigación sobre el discurso literario como un medio de construcción de identidades en el proceso de inclusión y aprendizaje del español como segunda lengua (EL2). El estudio se contextualizada en la Educación Secundaria Obligatoria y toma como punto de partida el análisis de las programaciones curriculares y protocolos de acogida diseñados para atender al alumnado inmigrante. Estas medidas, siguiendo el modelo integrado de la Unión Europea (Eurydice, 2004), priorizan las necesidades objetivas del adolescente inmigrante, entendidas como parámetros comunicativos y lingüísticos relacionados con la esfera académica, con el fin de incorporar al alumnado inmigrante en las clases ordinarias de las diferentes áreas curriculares. Sin embargo, el aprendizaje de una segunda lengua comporta también una serie de variables subjetivas que subyacen en el proceso de inclusión del alumnado inmigrante en la sociedad receptora. De acuerdo con Martín-Peris (2009, 19), las necesidades subjetivas son aquellas que tienen su origen en la configuración personal e individual de los procesos de aprendizaje, un conjunto de variables de tipo cognitivo, pero también de índole emocional, afectiva y social.

En lo que respecta a la presencia de la literatura en el aprendizaje del español como L2, la lectura literaria se propone para niveles intermedios -B1 del Marco Común Europeo de las Lenguas (2002) - a partir de lecturas graduadas y desde un enfoque historicista. A esta idea, se añaden las creencias de los profesores a considerar el texto literario como una modalidad discursiva muy compleja por su valor connotativo y poder sugerente, y argumentan que la escasa competencia 
lingüística del alumnado inmigrante principiante dificulta su acercamiento al texto literario (Mendoza, 1994; Martín-Peris, 2000; Mora-Sánchez, 2010; Calvo, 2010, 2011, 2012). Según Mora-Sánchez (2010) un alumno alcanzará un dominio completo de competencia lingüística del español cuando adquiera una competencia literaria que lo capacite para el acercamiento por sí mismo a los textos literarios de la lengua española. Para este autor, este objetivo conlleva no sólo el desarrollo de la competencia lingüística del hablante extranjero a través de la obra literaria, sino también la ampliación y enriquecimiento de su universo cultural y personal.

La revisión sobre la lectura literaria con lectores inmigrantes nos conduce a los trabajos de Fittipaldi (2012), Margallo (2012) y Arizpe (2012) -entre otros- que se han ocupado en estudiar la función y la utilidad de la literatura en la enseñanza de la lengua en contextos plurilingües. Del análisis de estos estudios se adivina el diseño de itinerarios lectores centrados en la proyección de la experiencia de la migración, de manera que el lector recién llegado a la sociedad receptora reflexione sobre su propia experiencia. Margallo $(2012,162)$ explica que "el encuentro con textos que elaboren simbólicamente la propia experiencia de desarraigo contribuye a hacer habitable el espacio psíquico y a elaborar el duelo por las pérdidas sufridas". Fittipaldi (2012) en su estudio sobre la experiencia de lectura compartida de Emigrantes (2007) con alumnos inmigrantes en el primer año de la Enseñanza Secundaria Obligatoria (E.S.O.), analiza los modos en que los jóvenes se apropian del texto, cómo sus experiencias previas inciden en la lectura y las reflexiones suscitadas sobre su proceso migratorio. Fittipaldi define este modo de apropiación como "clave personal o íntima”, y explica que esta categoría sería una manera de leer propia de los alumnos inmigrantes que se incorporan a la sociedad de acogida.

Teniendo en cuenta estos estudios y enfoques sobre la lectura literaria con adolescentes inmigrantes a manera de estado de la cuestión, en este artículo se proponen otras claves de lectura a partir del análisis de las respuestas lectoras del lector inmigrante ante los textos literarios. Los objetivos de la investigación son, por tanto:

- Establecer un marco de categorías para el análisis de las respuestas lectoras. Este propósito se desglosó en aplicar criterios culturales (Morgado, 2006; Goldin, 2006; Aguado, 2009; Tabernero y Mora, 2011 -entre otros) y estéticos (Ricoeur, 1975, 1996; Lewis, 2008) en la selección de los textos.

- Proponer claves de selección de textos literarios para alumnos inmigrantes de niveles A2 de competencia comunicativa en español a partir de los resultados del análisis.

\section{MARCO TEÓRICO}

Esta investigación entiende la educación inclusiva (Booth y Aisncow, 2002) como la manera de responder a la diversidad de los estudiantes creando entornos de aprendizaje en los escenarios educativos que minimicen las barreras lingüísticas y culturales. Así, se supera el modelo de integración y se incide en prácticas que 
conlleven la socialización y participación de jóvenes con diferentes lenguas y culturas a modo de una comunidad. En este sentido, Morgado (2006), Goldin $(2006,69)$ y Aguado $(2009,15)$ sugieren dinamizar conversaciones a partir de textos literarios que cuestionen y reconozcan patrones culturales dentro de la diversidad multicultural.

Por su parte, Meyer (1991) considera que el docente de una segunda lengua debería favorecer en sus alumnos la adquisición de un estadio transcultural que incita al acercamiento entre culturas heterogéneas y al establecimiento de vínculos más allá de la cultura misma, de manera que los alumnos construyan sus identidades.

Nuestra concepción de la diversidad cultural y lingüística se sitúa en la línea de pensamiento de estos autores y desde sus planteamientos se cimienta uno de los ejes sobre el que se articuló el itinerario propuesto: la necesidad de seleccionar un itinerario textual que incidiese en el cuestionamiento y análisis de los modelos culturales de la sociedad de acogida. También fueron claves los estudios sobre el hipertexto literario (Mendoza, 2004, 2010) como un instrumento para formar al lector inmigrante en el espacio intertextual de una cultura -en este caso, de la cultura receptora.

Además nos han servido de referencia las teorías de Bruner $(2002,2004)$ en relación al pensamiento narrativo y su concepción de la literatura como "un instrumento de la libertad, la luminosidad, la imaginación y, sí, la razón" (Bruner, 2004, 160). Así como las teorías de Rosenblatt (2002), Larrosa (2003), Petit (1999, 2001), Chambers (2007a, 2007b), Meek (2004) -entre otros. Estos teóricos desarrollan sus investigaciones a partir de la obra clásica de Lewis (1961), La experiencia de leer donde se explica que: "La experiencia literaria cura la herida de la individualidad, sin socavar sus privilegios. (...) cuando leo gran literatura me convierto en mil personas diferentes sin dejar de ser yo mismo" (Lewis, 2008, 140). Dicho estudio comporta uno de los aspectos más relevantes para nuestro trabajo en relación a la noción de la "lectura distanciada", la manera en que el lector se proyecta en el texto, se aleja de él o se acerca.

A su vez, hemos seguido los presupuestos de la Estética de la Recepción, la corriente de las Respuestas Lectoras (Sipe, 2000) y las teorías de la educación literaria de Mendoza (2004, 2010), Dueñas (2013) y Tabernero $(2005,2012)$.

\section{DISEÑO DE LA INVESTIGACIÓN}

\subsection{Contexto y participantes}

El trabajo de campo se inició en enero de 2008 hasta abril de 2011 en 4 aulas de español ubicadas en diferentes centros educativos de la Educación Secundaria Obligatoria de Aragón. En este escenario, el número total de informantes fue de 33: 3 profesores de las aulas de español con dilatada formación y experiencia en la enseñanza del español a alumnado inmigrante; y 30 adolescentes inmigrantes. Se constituyeron 4 grupos de lectura, compuestos entre 6 y 8 alumnos inmigrantes con edades comprendidas entre los 13 años a los 17, de diferentes lenguas y culturas de 
origen (chino, árabe, wolof, rumano, francés), con niveles A2 del MCEL (2002) en EL2.

\subsection{Metodología de la investigación}

Como opción metodológica se optó por la investigación-acción participante de cariz cualitativo/interpretativo y de corte etnográfico. Para ello, se utilizó una variada gama de estrategias cualitativas de recogida de datos que posibilitaron la triangulación de los datos durante el análisis: observación participante, entrevistas semiestructuradas y producciones escritas de los informantes.

La observación participante: se observaron un total de 81 sesiones de una hora desde enero del 2008 hasta abril del 2011. Para ello, se utilizaron grabaciones en audio, transcripciones de las conversaciones siguiendo el código de Cambra (2003) y notas de campo.

Entrevistas: al inicio del trabajo de campo y en la fase última de la recogida de datos se realizaron entrevistas semiestructuradas con cada uno de los 3 profesores de las aulas de español acerca del proceso de incorporación y aprendizaje del alumnado inmigrante, y sobre la lectura de textos literarios en el aula.

Antes de comenzar con las sesiones de lectura, se repartió a cada alumno un cuestionario para recabar información sobre edad, nacionalidad, tiempo de estancia en España, intereses lectores. En la última sesión, se conversó con los informantes sobre qué les había gustado del ambiente de lectura, los textos leídos y la escritura en el blog.

Producciones escritas. Los informantes en el blog de la investigación, http://leemosymas.blogspot.com.es/, escribieron 27 entradas a partir de las lecturas leídas y (29) comentarios libres a dichas entradas.

Para el análisis e interpretación de los datos optamos por el modelo aportado por Cambra $(2003,110)$ que se concreta en tres niveles: $\left.1^{\circ}\right)$ Análisis descriptivo inductivo de los datos. $2^{\circ}$ ) Análisis categórico, los datos obtenidos se organizaron en categorías utilizando el marco teórico de las Respuestas Lectoras, la revisión de las clasificaciones de respuestas lectoras en la discusión literaria de Sipe (2000) y el análisis del discurso. $3^{\circ}$ ) Análisis interpretativo, elaboración de informes en los que se recogen citas de los informantes que se consideran relevantes en relación a los objetivos de la investigación.

\subsection{Desarrollo de la sesiones}

El marco teórico ampara el enfoque asumido en el trabajo de campo, por lo que nos propusimos experimentar con los informantes el enfoque de lectura Dime de Chambers (2007b) ya que está orientado a lectores que se inician en la lectura de textos literarios. Para este autor, el interés de los niños y jóvenes por la lectura surge de una atmósfera emocional propiciatoria que incluye a personas, actividades, espacios, tiempos y textos que incitan a leer. 
$1^{a}$. La lectura en voz alta. La primera fase que se aplicó en el proceso de lectura de los textos literarios responde a la escucha de los adolescentes inmigrantes de las lecturas realizadas en voz alta por los investigadores. Para ello, se colocaron las sillas formando un círculo y los alumnos sólo tenían que escuchar, no se les entregaron los textos ni se les pidió que tomaran notas. Consideramos que esta modalidad de lectura como forma de la oralidad podría posibilitar el acercamiento de los jóvenes inmigrantes a la lectura literaria a través del mediador, quien ayuda a tender un puente entre la oralidad y la escritura. Estas ideas nos remitieron a las teorías de Ong (1987, 172): "la palabra oral es la primera que ilumina la conciencia con lenguaje articulado, la primera que une a los seres humanos entre sí en la sociedad". Por lo tanto, se incide también en la lectura en voz alta como una forma de vincular socialmente a los individuos.

$2^{\mathrm{a}}$. La discusión literaria a partir del repertorio de preguntas básicas que propone Chambers (2007b): ¿qué te ha gustado del texto?, ¿qué no te ha gustado?, ¿has encontrado algo extraño, nuevo? y ¿te ha recordado a algo? Se trató de potenciar un diálogo conversacional entre los informantes de manera que fueran éstos quienes seleccionaran los temas para hablar sobre lo leído. Los dos aspectos fundamentales son: escuchar la experiencia propia que tiene el lector con el texto y compartir esta experiencia con otros lectores.

$3^{a}$. La escritura en el entorno digital. La lectura activa, la oralidad y la discusión literaria fueron tendiendo un puente hacia la escritura. Sirva como evidencia este segmento de la conversación grabado durante la observación participante después de la lectura de "Apolo y Dafne" (2007):

10. Youness: yo no voy a cambiar, nada está bien como está, también podemos escribir un cuento cambiando las fechas que se enamoran los dos, me gusta la palabra "si no es mi mujer será mi árbol”, me haces una fotocopia y voy a escribir una historia.

Estas respuestas obtenidas nos condujeron a incorporar las herramientas de la Web 2.0, plataforma blogger $^{1}$, como soporte para la escritura. Para el diseño de esta fase, nos hemos nutrido de las aportaciones de Barthes (1987) sobre aquellas lecturas que engendran una escritura. También, han sido claves las investigaciones de Lluch $(2011,2012)$ en relación al enfoque comunicativo y participativo de la Web 2.0 y los estudios de Morduchowicz (2012) sobre la construcción de la identidad juvenil en la red social.

\subsection{Corpus literario experimentado}

El carácter emergente del diseño de la investigación nos permitió asumir las modificaciones pertinentes a la luz de los datos obtenidos y del análisis de los mismos. Así, identificamos dos fases en la selección de los textos: la primera se

\footnotetext{
${ }^{1}<\mathrm{http}: / /$ leemosymas.blogspot.com.es/>
} 
define a partir de los presupuestos de partida (criterios culturales y estéticos), y la segunda responde a un itinerario de contraste que se configuró desde los criterios de la oferta intercultural.

$1^{a}$. Fase en la selección. Seguimos como planteamiento inicial las ideas que subyacen de la siguiente cita de Petit $(2001,27)$ : "nunca es cuestión de encerrar a un lector en un casillero, sino más bien de lanzarle pasarelas, o mejor aún de darle ocasión de fabricar sus propias pasarelas, sus propias metáforas". Esta reflexión encierra en sí misma una concepción de la lectura literaria que se fundamenta en el concepto de metáfora como una manera de objetivar la historia personal, de construir sentidos y de desencadenar una actividad narrativa en el lector.

Por otra parte, a menudo en la selección de textos para adolescentes se priman los propósitos pedagógicos, esa tendencia escolar de transformar el discurso literario juvenil en un discurso didáctico y moral (Dueñas y Tabernero, 2004, 268-269). Esta vertiente didáctica de la literatura se aleja de nuestros propósitos ya que nos ha interesado buscar un corpus de obras que favoreciese la lectura activa y creativa, y la colaboración del bagaje literario del lector inmigrante. Para ello, el itinerario textual se fue modificando en función de las respuestas de los informantes en la conversación. No nos planteamos elaborar una lista de libros, sino que la discusión y la reflexión suscitada durante el proceso fueran las claves hacia la búsqueda de lecturas.

Así pues, comenzamos con la recopilación de los cuentos populares de Almodóvar Rodríguez (1983), Cuentos al amor de la lumbre. A modo de muestra, el siguiente segmento de la conversación sobre "Yo dos y tú uno":

1. Inv.: ¿Qué os ha gustado?

2. Yara: A mí me gustó lo de "Yo dos y tú uno" es muy

3. Inv: ¿es muy?

4. Youness: que da risas

5. Inv.: cómico

6. Yara: A mí me gustó cuando ha salido gritando y ha dicho que él se come los tres huevos

7. Youness: A mí me parece que no

8. Ahmed: No

9. Youness: Puede comer ella uno y medio y el hombre también uno y medio tiene que ser igual en todos los maridos

La discusión provocada en relación al cuestionamiento de referentes culturales, nos llevó a proponer el cuento XXXV "Lo que sucedió a un mancebo que casó con una muchacha muy rebelde", en El Conde Lucanor, Don Juan Manuel. Para ello, elegimos la edición y versión actualizada de Juan Viñedo (2004). Almodóvar recoge este cuento en "La mujer mandona", cuya lectura se realizó posteriormente y generó respuestas como las siguientes: 
80. Ahmed: no | sólo las mujeres hacen la comida | prefiero como en Senegal || yo trabajar y la mujer en casa para hacer la comida | limpiar | cuidar a los niños | así me gusta | es mejor para mí | yo no me gusta hacer la comida

81. Ruihao: pues eres muy vago

82. Ahmed: hacer la compra sí

83. Ruihao: machista

84. Youness: para mí no \| en Marruecos todos son machistas

85. Ruihao: en muchos países | aquí no | antes sí

Entendiendo, como se refiere Mendoza (2004), que el cuento tradicional es una manifestación cultural dentro de los modelos de la creación literaria, y resulta ser un modelo intertextual que reproduce un esquema discursivo básico y arquetípico, continuamos el itinerario con "El traje nuevo del emperador" de Andersen y el cuento maravilloso "La mano negra" de Almodóvar Rodríguez. Estas lecturas nos fueron tendiendo un puente hacia los clásicos que los integramos desde los postulados de Italo Calvino (1992). De este modo, leímos "Píramo y Tisbe" y "Apolo y Dafne" en la adaptación de Laurence Guillot (2007).

Encontramos en la obra de Xabier Docampo (2001), Cuando de noche llaman a la puerta, una posibilidad de acercar al lector inmigrante a los cuentos fantásticos de misterio, terror y sorpresa. En este sentido, los alumnos ya habían mostrado interés por el tema del miedo con "La mano negra".

Avanzamos con textos que permitieran apropiarse del pasado más próximo y sedimentarán las claves de la cultura de acogida. Obras que por su carácter híbrido, compuesto de texto e imagen, llevaran a la construcción de sentidos más allá del nivel de competencia lingüística del adolescente inmigrante (Tabernero, 2005). Así, leímos: Bestiario de greguerías de David Vela y Gómez de la Serna (2007), algunos de los poemas de Pablo Neruda e Isidro Ferrer (2006) en El libro de las preguntas, fragmentos de Mi familia (2006), algunos capítulos de Pippi Långstrump (2002) y de Manolito Gafotas (2009).

$2^{\mathrm{a}}$. Fase en la selección. Esta segunda fase facilitada por el diseño emergente de la investigación y el enfoque de lectura, se llevó a cabo con uno de los grupos de lectura después de cerrar el trabajo de campo correspondiente a la primera fase. La realidad de este escenario nos posibilitó continuar con el mismo grupo durante dos cursos. La revisión del itinerario inicial nos condujo a incorporar textos desde los criterios de la oferta intercultural del mercado editorial, nos referimos a títulos como: El león Kandinga (2009), Cena de rua (1999) y Emigrantes (2007) -recogidos en los catálogos de LIJ sobre la multiculturalidad. Sirva a modo de muestra este extracto de la discusión después de leer El león Kandinga:

30. Inv.: ¿os ha recordado a algo?

31. Aissatou: a una situación muy desagradable para mí que viví en Senegal, me gustó mucho el cuento del "mancebo"

32. Zineb: "Yo dos y tú uno" el que me gusta más es "Píramo y Tisbe" 
33. Aissatou: a mí me gustó el de la joven rebelde $\| \mid$ este cuento me recuerda a las fiestas de Senegal que hacían allí con máscaras y me daba mucho miedo

Este tipo de respuestas nos llevaron a buscar otros textos literarios con un cariz temático diferente, así leímos "Mi sobrina" de Daniel Nesquens y Emilio Urberuaga (2000), El túnel de Anthony Browne (2001), el "Gato negro" en Cuentos de imaginación y misterio, de Edgar Allan Poe, ilustrados por Harry Clarke (2009) y terminamos con Los Diarios de Adán y Eva, de Mark Twain y Francisco Meléndez (2010).

\section{RESULTADOS}

Los datos obtenidos se organizaron en categorías con el fin de establecer un marco propio para interpretar las respuestas de los informantes. El resultado fue un marco conceptual compuesto por seis categorías: analítica, intertextual, cultural, emocional, metafórica y creativa.

1.- Categoría analítica: respuestas metacognitivas como anticipaciones e inferencias.

2.- Categoría intertextual: relación del texto leído con otros textos.

3.- Categoría cultural: respuestas en las que el lector reflexiona y cuestiona modelos culturales.

4.- Categoría emocional: la conexión del texto con las emociones de los lectores participando en la historia y/o rechazando.

5.- Categoría metafórica: respuestas en las que el lector expresa placer por "cómo se cuenta la historia" evocando palabras, imágenes y metáforas.

6.- Categoría creativa: respuestas que engendran una escritura.

\section{Tabla 1: Categorías resultantes.}

Este marco de categorías ha resultado de gran utilidad para la concreción de una serie de parámetros en la selección de un itinerario. Asimismo, el carácter flexible del diseño de la investigación facilitó planificar las lecturas, experimentarlas, analizar las respuestas de los informantes y modificar el itinerario a la luz de los resultados. Por ello, el itinerario textual de la segunda fase sirvió para contrastar los criterios iniciales y confirmarlos. Así, títulos como El león Kandinga (2009), Cena de rua (1999) y Emigrantes (2007) por poner algunos ejemplos, son lecturas para otro tipo de receptor según indican la categoría cultural y la categoría emocional subyacentes en este estudio. Sirvan a modo de ejemplo las siguientes entradas en la plataforma virtual sobre Emigrantes ${ }^{2}$ :

Zineb: Me recuerda el dolor que han sufrido nuestros padres cuando han llegado a España. No me gusta porque me recuerda de tristeza y nada más.

Massamba: Me gusta para que lo lean los que no han salido hay que conocer el mundo.

${ }^{2}<$ http://leemosymas.blogspot.com.es/2010_12_02_archive.html> 
Estas lecturas supusieron para los adolescentes inmigrantes resonancias muy directas a su experiencia vital como hijos de emigrantes. La identificación explícita entre texto, cultura y vida personal del joven inmigrante se muestra como variable significativa en la selección de obras para jóvenes inmigrantes.

Por lo tanto, se proponen seis claves a modo de guía para orientar al mediador, en el contexto que nos ocupa será el profesor del aula de español, en la selección de textos literarios para lectores adolescentes inmigrantes de EL2:

\section{El cuento popular ${ }^{3}$}

Los dispositivos textuales del cuento popular: argumentos breves con una trama sencilla, pocos personajes y por lo general esquemáticos, acción escasa pero muy concentrada, estructura tradicional (planteamiento, nudo y desenlace), la repetición de los principios y finales, la atemporalidad, el humor para afrontar situaciones cotidianas; todas estas características propician la interacción del lector inmigrante con el texto activando su intertexto, apropiándose de esquemas narrativos y asociando elementos discursivo-textuales y lingüísticos-pragmáticos.

Las categorías intertextuales y culturales obtenidas muestran proyecciones que realizaron los adolescentes inmigrantes de sus referentes culturales a partir de los cuentos de costumbres, así como el discurso transcultural que se originó al hilo de sus intervenciones. De esta manera, los conflictos planteados por los arquetipos narrativos les llevaron a cuestionar patrones culturales y a proponer de manera cooperativa soluciones al mundo representado en la ficción popular. En este sentido, la distancia que ofrece el humor del cuento popular permite durante la lectura momentos de relax en los que el dramatismo y la intensidad de la historia encuentran pausas de expansión y de risa colectiva que sirve para cohesionar al grupo de lectura. El humor sirve para transgredir el orden establecido y abordar temas como la autoridad en el matrimonio, la propiedad privada, el culto a los muertos, entre otros. Además, los cuentos tradicionales son historias comunes a diversos pueblos y culturas que expresan y satisfacen una serie de capacidades y necesidades propias del ser humano de cualquier época y lugar: la imaginación y la fantasía, el misterio y la atracción por lo maravilloso y desconocido, la expresión de emociones, la distracción y el entretenimiento. Por otra parte, el lenguaje de los cuentos es universal y, por ello, se convierte en uno de los elementos de conexión entre culturas.

\section{Las reescrituras de los clásicos ${ }^{4}$}

Muchos de los jóvenes desconocían los textos clásicos aun siendo leyendas universales, sin embargo interaccionaron con las fábulas, reflexionaron, se emocionaron con el lenguaje literario, se apropiaron de palabras y escribieron sus

\footnotetext{
3 <http://leemosymas.blogspot.com.es/search?updated-min=2010-01-

01T00:00:00\%2B01:00\&updated-max $=2010-02-01 \mathrm{T00}: 00: 00 \% 2 \mathrm{~B} 01: 00 \&$ max - results $=4$

4 <http://leemosymas.blogspot.com.es/2010_05_19_archive.html>
} 
propias narraciones o reescribieron a partir de la voz de algunos de los personajes narrativos. Asimismo, la lectura coadyuva a ampliar el léxico de los alumnos y a familiarizarse con las estructuras narrativas. Señalamos procesos de apropiación, recuperación de frases literarias del hipotexto en los hipertextos creados y secuencias potencialmente adquisitivas surgidas en las conversaciones y en las producciones escritas de los alumnos en el blog.

Por lo tanto, creemos que no pueden faltar los textos clásicos ya que son universales, vigentes y actuales; también "para entender quiénes somos y adónde hemos 1legado" (Calvino, 1992, 19). Sin embargo, para aproximar al lector inmigrante a la obra clásica, proponemos las adaptaciones siguiendo los estudios de Sotomayor $(2005,2013)$ como una forma de reescritura de los textos clásicos que se acomoda a un receptor, a una nueva lengua y a un nuevo contexto.

\section{El subgénero del suspense, el miedo o terror ${ }^{5}$}

Los resultados del análisis reflejan un gusto también de los lectores inmigrantes por el subgénero del suspense y el miedo, por lo que nos lleva a identificar otra clave para la selección de obras literarias. Por ejemplo, el suspense contenido y el desenlace feliz del cuento maravilloso "La mano negra", los relatos de X. Docampo (1996) en Cuando de noche llaman a la puerta y Cuentos de imaginación y misterio, de Edgar Allan Poe, ilustrados por Harry Clarke (2009), despertaron curiosidad y movieron las emociones de los lectores. Sirva como muestra el siguiente segmento de la conversación sobre "El gato negro" de Poe:

1. Inv. ¿Os ha gustado?

2. Binta: SI

3. Zineb: la manera de contarlo y el miedo me gustan los cuentos de miedo es muy fuerte cuando mata a su mujer

4. Aissatou: todo

5. Binta: me gusta pero un poco triste y fuerte

6. Zineb: el hombre es muy malo

7. Aissatou: ¿era alcohólico?

8. Zineb: la mujer aguanta a su marido

9. Binta: un poco triste, la forma de leer en voz alta, esos dibujos me dan mucho miedo

10. Zineb: quería llegar al final

${ }^{5}<$ http://leemosymas.blogspot.com.es/2010/03/el-cumplemuertes-x-docampo.html> 


\section{El libro como objeto estético y la ilustración como lenguaje y estrategia narrativa ${ }^{6}$}

La incorporación de la ilustración en algunas obras de la literatura juvenil actual ayuda a acercar el libro al adolescente inmigrante. Del mismo modo, los paratextos como los títulos e intertítulos, cubiertas y guardas generan expectativas en el lector inmigrante y éste se convierte en un participante activo en la construcción de sentido. La aplicación de la categoría analítica, emocional y metafórica reporta dos claves fundamentales: el libro como objeto estético y la ilustración como clave que facilita la construcción de significados en lectores que se inician en la lectura de textos en su L2. Así lo reflejan las respuestas obtenidas a la obra El libro de las preguntas (2006), que supuso asombro y sorpresa en los círculos de lectura. La pregunta como una buena invitación al conocimiento del individuo en una edición hermosa, inteligente, para un lector sensible que se atreve a jugar con el lenguaje de las imágenes:

1. Inv: ¿qué os parece la cubierta?

2. Zineb: nos va a hacer preguntas y tenemos que contestar

3. Binta: me gusta la cubierta

4. Inv: ¿qué os gusta de la cubierta?

5. Kadiatou: me gustan los dibujos

6. Aissatou: los dibujos

7. Massa: los peces, el pescador

8. Aissatou: el pescador

9. Zineb: nosotros vamos a pescar preguntas

10. Aissatou: o ¿no?

Otra muestra de estas dos claves, la encontramos en las respuestas al Bestiario de greguerías (2007). En este caso, los dibujos simples y cómicos, las personificaciones, ayudaron a los lectores inmigrantes a entender el sentido de la greguería y a explorar la función lúdica del lenguaje. Posiblemente sin la combinación palabra e imagen, estos textos serían complejos para estos jóvenes. La lectura compartida entre el facilitador y los lectores ayuda a entender las funciones narrativas del texto y de la imagen. En este sentido, cabe citar El túnel de Anthony Browne (2001), en el que las ilustraciones aportan pistas para comprender el texto. Así, en "ese leer mirando" (Tabernero, 2009), las referencias intertextuales a los cuentos de hadas, la interpretación simbólica, el uso de diferentes técnicas artísticas, la relación entre el color y los cambios en la atmósfera de la narración, convierten a este libro-álbum en otra lectura potencialmente rica para la creación de una comunidad interpretativa.

6 <http://leemosymas.blogspot.com.es/2010/05/bestiario-de-greguerias-ramon-gomezde.html> y <http://leemosymas.blogspot.com.es/2011/01/el-tunel-anthony-browne.html> 


\section{El humor en la $\mathrm{LIJ}^{7}$}

El humor absurdo conlleva transgredir las leyes lógicas y racionales que organizan nuestra comprensión del mundo y desmitificar aspectos temáticos y formales de la tradición literaria. Por otra parte, supone un distanciamiento del didactismo tradicional de la LIJ. Tal y como señala Dueñas (2011), el humor ayuda a formar al lector adolescente mejor que otros procedimientos aparentemente más educativos, ya que este discurso más arriesgado solicita la participación del lector como estrategia textual y ofrece un juego intertextual. A este respecto, obras como Diecisiete cuentos y dos pingüinos (2000) o Mi familia (2006) conllevaron una lectura distanciada a través del humor como clave textual. Por ejemplo, sobre Mi familia decían:

1. Inv.: ¿Qué os ha gustado de este libro?

2. Youness: A mí lo que me ha gustado son las palabras I por ejemplo I dice de mi casa a la fuente estaba como a dos kilómetros y el sol a millones de kilómetros / hay muchas palabras parecidas que repite

3. Ruihao: Ah:: todo::

4. Youness: Algunas frases y cómo cuenta el narrador la historia II es gracioso

Otro texto en el que la presencia del humor puede contribuir en la formación del lector adolescente, podría ser la obra de Mark Twain y Francisco Meléndez (2010), Los Diarios de Adán y Eva, relato en el que se presentan desde el humor las contradicciones que genera la convivencia. En el caso de esta investigación, esta lectura engendró la entrada titulada "El Diario de Caín" en el que su autora adopta la primera persona para reescribir el mundo de Caín plagado de palabras, frases, metáforas y marcas discursivas del hipotexto. Por tanto, la informante -a partir de la lectura en voz alta- se apropia de recursos narrativos y estrategias discursivas para tejer su texto escrito.

\section{CONCLUSIONES}

Esta investigación nos ha reportado nuevos acercamientos al adolescente inmigrante como lector de textos literarios en EL2. En este encuentro ha sido crucial situar en primer plano la experiencia de lector inmigrante al escuchar el texto y compartir esa experiencia con otros jóvenes, primero desde la oralidad en la discusión literaria y después en el entorno virtual como soporte para su escritura. Las herramientas que ofrece la Web 2.0 se muestran como un medio de conexión e interacción entre jóvenes adolescentes estableciendo vínculos más allá de sus culturas, creando, por tanto, un espacio transcultural.

\footnotetext{
$7<$ http://leemosymas.blogspot.com.es/2011/04/los-diarios-de-adan-y-eva-de-marktwain.html>
} 
Los resultados obtenidos muestran que la atención a la diversidad cultural y lingüística depende más de las estrategias de mediación y del enfoque de lectura que de la selección de textos. Las seis variables que se identifican en este estudio se sustentan en dos conceptos: la "lectura distanciada" y el "como si" que engloba la metáfora, elementos transcendentes en la lectura literaria. Esperamos que estas claves le sirvan al mediador para abrir nuevos caminos y encuentros entre el lector inmigrante y el texto literario. Pero sin duda, serán la discusión y la reflexión suscitada durante el proceso de recepción de la obra literaria en el marco de la comunidad interpretativa, las guías hacia la búsqueda continua de lecturas.

\section{BIBLIOGRAFÍA}

AguADO, $M^{\mathbf{a}}$ Teresa (2009): "El enfoque intercultural como metáfora de la diversidad en educación", en Educación Intercultural. Perspectivas y propuestas, T. Aguado y M. Del Olmo (eds.), Madrid, Ramón Areces, 13-29.

ANDERSEN, Hans Christian (2005): "El traje nuevo del emperador", Cuentos completos, Madrid, Cátedra.

ARIZPE, Evelyn (2012): "Entre imágenes y palabras: la investigación que promueve comunidades lecturas inclusivas y creativas", en La literatura que acoge: Inmigración y lectura de álbumes, T. COLOMER y M. FITTIPALDI (coords.), Venezuela, Banco del Libro - GRETEL - SM, 44-68.

BARTHES, Roland (1987): El susurro del lenguaje. Más allá de la palabra y la escritura, Barcelona, Paidós Comunicación.

BoOTH, Tony y AISNCOW, Mel (2002): Index For Inclusion: Developing Learning and Participation in Schools, Bristol, CSIE.

BRowne, Anthony (2001): El túnel, México, Fondo de Cultura Económica.

BRUNER, Jerome (2002): Making Stories. Law, Literature, Life, New York, Farrar, Straus and Giroux.

BRUNER, Jerome (2004): Realidad mental y mundos posibles. Los actos de la imaginación que dan sentido a la experiencia, Barcelona, Gedisa.

CALvino, Italo (1992): Por qué leer a los clásicos, Barcelona, Tusquets.

CALVo, Virginia (2010): "La lectura de textos literarios en el aula de español", en Lenguaje y Textos, 32, 113-119.

CALvo, Virginia (2011): "Claves para seleccionar un itinerario constructor de identidades en el proceso de acogida y aprendizaje del español como segunda lengua", en Ocnos, 7, 123-137.

CALVo, Virginia (2012): El discurso literario: construcción de identidades en el proceso de acogida y aprendizaje del español como segunda lengua, Zaragoza, Universidad de Zaragoza. Tesis doctoral inédita.

CAMBRA, Margarida (2003): Une approche ethnographique de la classe de langue, Paris, Didier.

CHAMBERS, Aidan (2007a): El ambiente de la lectura, México, FCE. 
CHAMBers, Aidan (2007b): Dime, México, FCE.

DOCAMPO, Xavier (2001): Cuando de noche llaman a la puerta, Madrid, Anaya.

DUEÑAS, José Domingo (2011): "Fomentar el deleite: el humor en la literatura juvenil", en Anuario de investigación en literatura infantil y juvenil, 9, 21-31.

DUEÑAS, José Domingo (2013): "La educación literaria. Revisión teórica y perspectivas de futuro", en Didáctica (Lengua y Literatura), Publicaciones Universidad Complutense, 25, 135-156, doi: http://dx.doi.org/10.5209/rev_DIDA.2013.v25.42239, [consulta el 10 de febrero de 2014].

DUEÑAS, José Domingo y TABERNERO, Rosa (2004): "La narrativa juvenil en los últimos veinte años: entre luces y sombras", en Aspectos didácticos de Lengua y Literatura 13, M. SANJUÁN (coord.), Zaragoza, ICE-Universidad de Zaragoza, 221-294.

EURYDICE (2004): La integración escolar del alumnado inmigrante en Europa, Bruselas, Eurydice.

FITTIPALDI, Martina (2012): "La categorización de las respuestas infantiles antes los textos literarios. Análisis de algunos modelos y propuesta de clasificación", en La literatura que acoge: Inmigración y lectura de álbumes, T. COLOMER y M. FITTIPALDI (coords.), Venezuela, Banco del Libro - GRETEL - SM, 69-86.

GuILlOT, Laurance (2007): Las metamorfosis de Ovidio, Madrid, Clásicos a medida, Anaya.

GolDIN, Daniel (2006): Los días y los libros. Divagaciones sobre la hospitalidad de la lectura, México, Paidós.

InSTITUTO CERVANTES (2002): Marco común europeo de referencia para las lenguas: aprendizaje, enseñanza, evaluación, Madrid, Instituto Cervantes.

LAGO, Ángela (1999): Cena de rua, Caracas, Eraké.

LARROSA, Jorge (2003): La experiencia de la lectura, México, FCE.

LEWIS, Clive Staples (2008): La experiencia de leer (4 ed.), Barcelona, Alba Editorial.

LINDGREN, Astrid (2010): Pippi Langstrump, Barcelona, Juventud.

LINDO, Elvira (2004): Manolito Gafotas, Madrid, Alfaguara.

LLUCH, Gemma (2011): Proyecto: Lectura, escritura y desarrollo en la sociedad de la información, Colombia, Colección Lectura y Escritura, CEARLAC.

LLUCH, Gemma (2012): Del oral, audiovisual y digital a la lectura (y la escritura) en secundaria, Madrid, Fundación SM.

MARGALlo, Ana María (2012): "Qué literatura para los recién llegados", en $L a$ literatura que acoge: Inmigración y lectura de álbumes. T. COLOMER y M. FITTIPALDI (coords.), Venezuela, Banco del Libro - GRETEL - SM, 144-171.

MARTín-PERIS, Ernesto (2000): "Textos literarios y manuales de enseñanza de español como lengua extranjera", en Lenguaje y Textos, 16, 101-131.

MARTíN-PERIS, Ernesto (2009): "Formar para enseñar lenguas a no nativos. La preparación del profesor de segundas lenguas a inmigrantes", en II Jornadas sobre 
Lenguas, Currículo y Alumnado inmigrante, I. BALLANO (coord.), Bilbao, Universidad de Deusto, 13-31.

MEEK, Margaret (2004): En torno a la cultura escrita, México, FCE.

MENDOZA, Antonio (1994): "La selección de textos literarios en la enseñanza de ELE. Justificación didáctica", en Las lenguas extranjeras en la Europa del Acta Única, Barcelona, ICE-UAB, 126-133.

MENDOZA, Antonio (2004): La educación literaria. Bases para la formación de la competencia lecto-literaria, Málaga, Ediciones ALJIBE.

MENDOZA, Antonio (2010): "La lectura del hipertexto literario. El despliegue de referentes, conexiones e hipervínculos en la formación del lector", en El lector ante la obra hipertextual. (Un análisis de la interacción y de la metacognición en la recepción), A. MENDOZA y C. ROMEA (coords.), Barcelona, Horsori, 143-174.

MEYER, H. (1991): "Developing transcultural competence: case studies advanced language learners", en Mediating languages and cultures: towards and intercultural theory of foreign language education, D. BUTTJES y M. BYRAM (eds.), Clevedon, United Kingdom, Multilingual Matters, 142-144.

MORA-SÁNCHEZ, Miguel Ángel (2010): "Reseña crítica, ELE”, en Revista Oficial de Idiomas, Alicante, Disponible en Web: http://eoialicante.edu.gva.es/ revista_eoi/?page_id=646, [consulta el 12 de febrero de 2011].

MORDUCHOWICZ, Roxana (2012): Los adolescentes y las redes sociales. La construcción de la identidad juvenil en Internet, Buenos Aires, FCE.

MORGADO, Margarida (2006): "Nuevos libros, viejos libros: una perspectiva desde la Educación Intercultural", en Primeras Noticias, 216, 7-20.

NERUDA, Pablo y FERRER, Isidro (2006): El libro de las preguntas, Valencia, Media Vaca.

NESQUENS, Daniel y ARQUILÉ, Elisa (2006): Mi familia, Madrid, Anaya.

Nesquens, Daniel y URBeruagA, Emilio (2000): Diecisiete cuentos y dos pingüinos, Madrid, Anaya.

OFOFO, Boniface y ARGUILÉ, Elisa (2009): El león Kándiga, Sevilla, Kalandraka.

ONG, Walter (1987): Oralidad y escritura. Tecnologías de la palabra, México, FCE.

PETIT, Michèle (1999): Nuevos acercamientos a los jóvenes y la lectura, México, FCE.

PETIT, Michèle (2001): Lecturas: del espacio íntimo al espacio público, México, FCE.

POE, Edgar Allan y ClaRKe, Harry (2009): Cuentos de imaginación y misterio, Barcelona, Libros del Zorro Rojo.

RICOEUR, Paul (1975): La metáfora viva, Madrid, Trotta.

RICOEUR, Paul (1996): Tiempo y narración, Volumen III, Madrid, Siglo Veintiuno. RODRíGUEZ, Almodóvar (1983): Cuentos al amor de la lumbre, Madrid, Anaya. RosenBlatT, Louise (2002): La literatura como exploración, México, FCE. 
SIPE, Lawrence (2000): "The Construction of Literary Understanding by First and Second Graders in Oral Response to Picture Storybook Read-Alouds", Reading Research Quarterly 35 (2), 252-275.

SOTOMAYOR, María Victoria (2005): "Literatura, sociedad, educación: las adaptaciones literarias", en Revista de Educación. Sociedad lectora y educación, $\mathrm{n}^{\mathrm{o}}$ extraordinario, 217-238.

SOTOMAYOR, María Victoria (2013): “¿Qué hacemos con los clásicos? Algunas reflexiones para futuros docentes, en Lenguaje y Textos, 38, 29-38.

TABERNERO, Rosa (2005): Nuevas y viejas formas de contar: el discurso narrativo infantil en los umbrales del siglo XXI, Zaragoza, Prensas Universitarias de Zaragoza.

TABERNERO, Rosa (2009): "Leer mirando. El libro-álbum en la promoción de hábitos lectores. Claves para una poética de su lectura", en I Encuentro Internacional de Estudio y Debate. Literatura Infantil y Matices, Tarazona, Fundación Tarazona Monumental, 9-44.

TABERNERO, Rosa (2012): "La hipertextualidad como fundamento de construcción en la literatura "iluminada": La formación del lector en el libro-álbum y en el libro ilustrado", en Leer Hipertexto. Del marco hipertextual a la formación de lector literario, A. MENDOZA (coord.), Barcelona, Octaedro, 121-134.

TABERNERO, Rosa y MORA, Luisa (2011): El libro infantil y juvenil y sus claves desde la diversidad cultural en la escuela y las bibliotecas españolas. IV Congreso Ibérico de OEPLI sobre el Libro Infantil y Juvenil: Leo Diferente: El Libro Infantil y Juvenil desde la Diversidad Cultural, San Sebastián: Departamento de Cultura del Gobierno Vasco.

TAN, Shaun (2007): Emigrantes, Arcos de la Frontera, Barbara Fiore.

Twain, Mark y MelÉndeZ, Francisco (2010): Los Diarios de Adán y Eva, Barcelona, Libros del Zorro Rojo.

Vela, David y GÓMEZ De LA SERNA, Ramón (2007): Bestiario de greguerías, Madrid, ACVF.

VIÑEDO, Juan (2004): Cuento XXXV Lo que sucedió a un mancebo que casó con una muchacha muy rebelde, en El Conde Lucanor, Don Juan Manuel, edición y versión actualizada de Juan Viñedo, Biblioteca Virtual Miguel de Cervantes. 